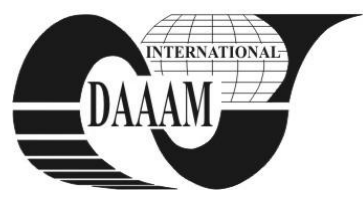

Annals of DAAAM for 2011 \& Proceedings of the 22nd International DAAAM Symposium, Volume 22, No. 1, ISSN 1726-9679 ISBN 978-3-901509-83-4, Editor B. Katalinic, Published by DAAAM International, Vienna, Austria, EU, 2011 Make Harmony between Technology and Nature, and Your Mind will Fly Free as a Bird

\title{
PORTABLE HARDNESS TESTER
}

\section{GUTT, S[onia]; GUTT, G[heorghe]; SEVERIN, T[raian] - L[ucian]; POROCH - SERITAN, M[aria]; MIRONEASA, S[ilvia] \& OROIAN, M[ircea] A[drian]}

\begin{abstract}
The hardness tester presented in the paper is a portable testing equipment for hardness test with static load, for metals and metal alloys, being able to operate both with manual applied load and with applied load through a mobile table of its own frame or through work table of a machine tool, in the latter case hardness tester being mounted on machine head that processes components. In terms of operating principle, hardness tester is based on determination of reaction force of tested material as an expression of its hardness. From constructive point of view hardness tester is presented as a modular form consisting in a probe, which contains spring loading system of indenter, a force sensor, and an electronic unit.
\end{abstract}

Key words: hardness, force measurement, materials, indentation

\section{INTRODUCTION}

In order to determine the hardness of materials on the principle of force measurement the invention proposal A00/873/2010, entitled „Apparatus for testing and characterization of advanced materials", authors Gutt S, et.al., is known. This apparatus allows both hardness determination and in addition other important material characteristic sizes such as: modulus, work of deformation, creep tendency, the equipment has a loading-unloading kinematics by engine instead, it is not portable and has a high cost price. Also for hardness determination and other important characteristics of material Martens hardness tester (DIN EN ISO 14.577), (Amstrong et.al., 2005), (Gutt et al. 2000), (Czichos et.al. 2006) is known. Another solution based on the measurement of reaction force of material is a portable hardness tester UCI (Weiler et.al 1990). Common disadvantage of these presented solutions is the high cost of equipment, (Gutt S. et.al. 2011), (Severin T.,et.al. 2010)

\section{EXPERIMENTAL}

Electronic apparatus is intended to hardness detrmination of metals and alloys in field and laboratory conditions using a portable manual structure with aid of the material is tested by a diamond indenter, hardness being expressed by its resistance to indenter action. Reaction force of tested material is measured by a force sensor serially connected in loading indenter circuit. Structure of hardness tester consists in a sonde, an electrical connection cable and an electronic unit, figure 1, in turn probe, figure 2, consists of a cylindrical body 1 , provided with a rubber sleeve 2 , an indenter 3 which acts on tested material 4 , a portindenter 5 , a loading rod 6 , a mounting base 7 , a guide bush 8 , a mounting spring 9, a guide bush with balls 10 , a preloading spring 11 , a contact rod 12 , a tensioning nut 13 , a torque cell with resistive sensors 14 , electrical connector 22 and an electronic unit.

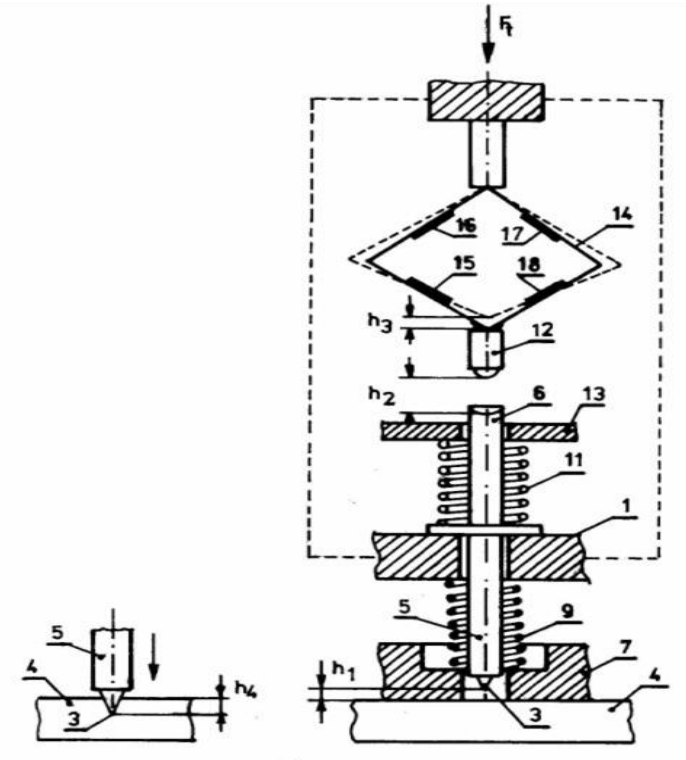

Fig.1. Block diagram of portable hardness tester. 1-cylindrical body, 3-indenter, 4-tested material, 5-indenter, 6-load rod, 7mounting base, 9- setting spring, 11- preload spring 12-contact rod, 13- tensioning nut, 14-torque cell, 15,16,17,18electroresistive sensors

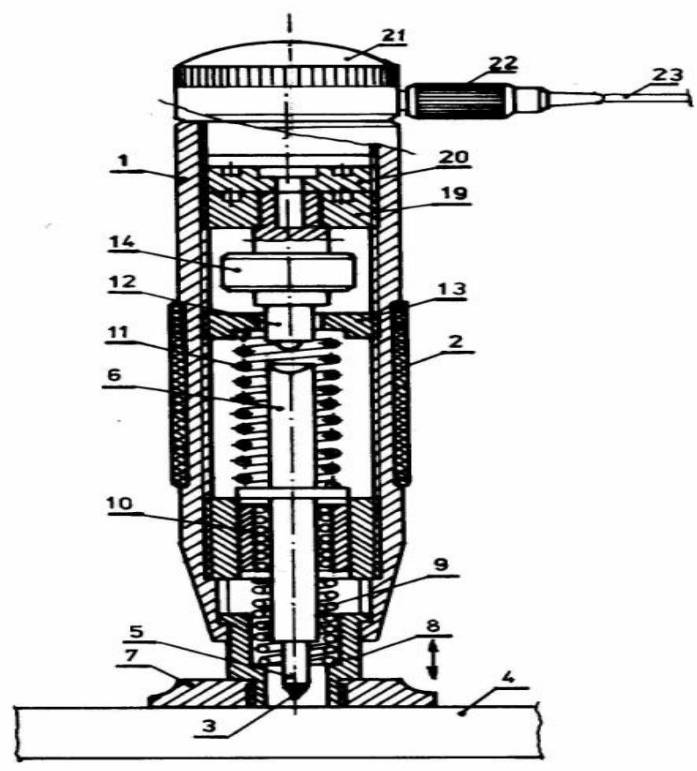

Fig.2. Section through hardness tester probe. 1-cylindrical body, 2-rubber sleeve, 3-indenter, 4-tested material, 5portindenter, 6-load rod, 7-mounting base, 8- guide bush, 9setting spring, 10-ball guide bush, 11- preload spring, 12contact rod, 13- tensioning nut,14-dynamometer cell, 19,20nuts, 21-lock body, 22-connector, 23-electric cable 
In the case of working in laboratory the equipment is completed with a fixed structure, figure.3, formed by a frame machine 24 , a cylindrical column 25 , a transverse body 26 , two grip knife 27,28 , a lifting lever 29 and a mass 30 for hardness tested sample.

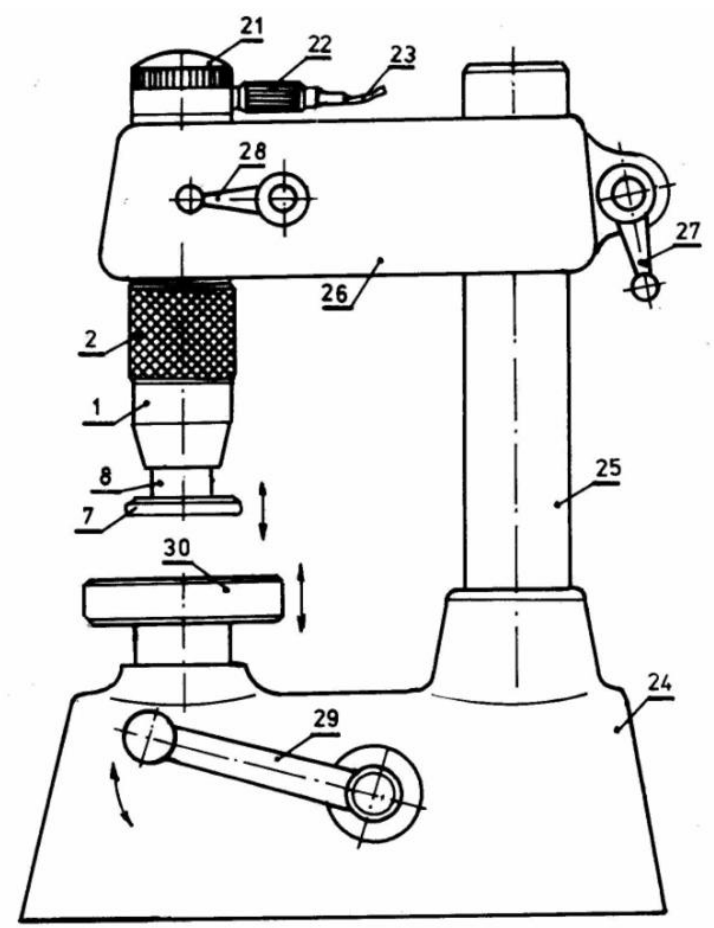

Fig.3. Laboratory measurement structure with hardness tester probe fixed on frame with down-shift sample.1-cylindrical body, 2-rubber sleeve, 7-mounting base, 8-bush guiding, 21-closing body, 22connector, 23-electric cable, 24-frame, 25-cylindrical column, 26-cross body, 27,28-knife grip nut, 29-lifting handler, 30-mobile mass for tested sample

\section{RESULTS AND DISCUSSION}

Operation with hardness tester is as follows: at portable mode probe is pressed manually through mounting base 7 on tested material 4 , at laboratory working mode, tested material 4 is pressed onto the base 7 until there is a pronounced strength. After the described testing fixing spring 9 is compressed first with the road $h_{l}$, and then preloading spring 11 with a road $\mathrm{h}_{2}$ still having held dynamometer cell compression 14 what it causes an elastic deformation on a distance $h_{3}$, part of the total applied force is consumed to ensure a deep $\mathrm{h}_{4}$ of penetration of indenter 3 in tested material 4 . Under these conditions the equation of total displacement $h_{t}$, as a result of preload spring 11 compression and torque cell 14 , has the expression:

$$
h_{t}=h_{2}+h_{3}
$$

and forces $F_{t}$ and $F_{t x}$, measured by resistive sensors $15,16,17$ and 18 have the expression:

$$
\begin{aligned}
& F_{t}=K_{1} \cdot h_{t} \\
& F_{t x}=K_{1} \cdot h_{t}-K_{2} \cdot h_{4}
\end{aligned}
$$

where: $F_{t}$ - is measured force for spring 11 compression and elastic element of dynamometer cell 14 in conditions that $h_{4}=$ 0 (infinite hardness); $F_{t x}$-is measured force in the material conditions of penetration of indenter 3 in tested material 4 on a deep $h_{4}, K_{1}$ - average characteristic of the spring 11 and of elastic element of dynamometer cell 14 , and $K_{2,-}$ is an elastic constant of tested material 4 and directly proportional with its modulus. As shown in equation (3) penetration depth value $\mathrm{h}_{4}$ (value that is inversely proportional to the hardness of tested material 4 , can be expressed in value of force $F_{t x}$ if the value of force $F_{t}$ is known. To achieve the last condition a simple device is used that is prestressed spring 11 and elastic element of dynamometer cell 14 with a predetermined value $h_{5}$, which may be equal to the total height of indenter, but can be another constant value verified at constant intervals. A standard curve made with standard hardness plates is used, electronically saved and with an appropriate program, the microprocessor of electronic unit converts the value $h_{4}$ in units of hardness that are digitally displayed. Material hardness value is the expression of ratio:

$$
H=\frac{K}{h_{4}}
$$

It should be noted that the road traveled by interchangeable mounting base 7 and guide bushing 8 only serves to compress spring 9 to prevent the movement of tested material 4 during its application by indenter 3. Compression of this spring is not included in the balance of forces because it does not act on the dynamometer cell 14 .

\section{CONCLUSION}

Portable described hardness tester is an efficient portable advanced tool for hardness determination of metallic materials on the principle of linking reaction force with tested material hardness, thereby design simplicity is increased, and measurement errors and price are reduced. Execution device in a compact modular unit allows adaptation of hardness tester to various issues and places of hardness measurements. Also, mechanization of loading-unloading cycle allows the use of described hardness tester for automatic hardness control on production lines.

\section{REFERENCES}

Amstrong R., Ferranti L., jr., Thadhani N., N., (2005), Elastic/plastic/cracking indentation behavior of hard materials,International Journal of Refractory Metals \& Hard Materials 24, p. 11-16

Czichos H., Saito T.,Smith L., (2006) Handbook of Material Measurements Methods, Springer Verlag Berlin, p. 311-333

Gutt G., Gutt S., (2000) Testing and characterization of metallic materials, (Romanian), Editura Tehnica Bucuresti, p. $204-311$

Gutt S., Gutt G., Severin T., L., Mironeasa S., Poroch -Seritan M., Alexuc F. (2011), Equipment for material testing and advanced characterization, DAAAM 2011

Gutt S., Gutt G., Severin T., L., Gutt A., (2010) Apparatus for material testing and advanced characterization, (Romanian), Patent proposals OSIM Bucuresti, A00/873/2010

Weiler W., Leeb D.H., Müller K., Rupp D.,M., (1990) Härteprüfung, an Metallen und Kunsststoffen , 2. Auflage, Experverlag Ehningen bei Böblingen, p.60-100

Severin, T, Gutt, S, Poroch - Seritan, M., Gutt,G, Gutt S., Stroe, S.,G., (2010). Study the technological parameters influence on the hardness of aNi-W alloys obtained by galvanic deposition, Annals of DAAAM for 2010 \& Procedings of the 21st International DAAAM Symposium, Viena 2010, p. 1011-1013

*** DIN EN ISO 14.577 - Instrumentierte Eindringprüfung 